\title{
Comparison of shipborne GNSS-derived precipitable water vapor with radiosonde in the western North Pacific and in the seas adjacent to Japan
}

\author{
Yoshinori Shoji ${ }^{*} \mathbb{B}$, Kazutoshi Sato ${ }^{2}$, Masanori Yabuki ${ }^{3}$ and Toshitaka Tsuda ${ }^{3}$
}

\begin{abstract}
We installed two global navigation satellite system (GNSS) antennas on a research vessel, the RYOFU MARU of the Japan Meteorological Agency, and conducted experimental observations to assess the GNSS-derived precipitable water vapor (PWV) from October 19, 2016, to August 6, 2017. One antenna was set on the mast (MAST), while another antenna was set on the upper deck (DECK). The GNSS analysis was conducted using the precise point positioning procedure with a real-time GNSS orbit. A quality control (QC) procedure based on the amount of zenith tropospheric delay (ZTD) time variation was proposed. After the QC was applied, the retrieved PWVs were compared to 77 radiosonde observations. The PWVs of MAST agreed with the radiosonde observations with a $1.7 \mathrm{~mm}$ root mean square (RMS) difference, a $-0.7-\mathrm{mm}$ bias, and 3.6\% rejection rate, while that of DECK showed a 3.2, $-0.8 \mathrm{~mm}$, and 15.7\%. The larger RMS and higher rejection rate of DECK imply a stronger multi-path effect on the deck. The differences in the GNSS PWV versus radiosonde observations were compared to the atmospheric delay, the estimated altitude of the GNSS antenna, the vessel's moving speed, the wind speed, and the wave height. The atmospheric delay and GNSS antenna altitude showed moderate correlation with the differences. The results suggest the kinematic PPP's potential for practical water vapor monitoring over oceans worldwide. At the same time, from the growing negative biases with the PWV value and with estimated antenna altitude, it could be inferred that the difficulty grows in separating the signal delay from the vertical coordinate under high-humidity conditions.
\end{abstract}

Keywords: GNSS meteorology, Precipitable water vapor, Kinematic precise point positioning, Real-time orbits

\section{Introduction}

Nowadays, global navigation satellite systems (GNSSs), such as the US Global Positioning System (GPS), are fundamental infrastructure for navigation, positioning, and timing. These systems also serve as an accurate continuous water vapor monitoring tool. In particular, multiple studies have been conducted to assess the accuracy of GNSS-derived vertically integrated water vapor in the atmosphere (precipitable water vapor: PWV) and have confirmed its practicality (e.g., Bevis et al. 1992; Shoji

\footnotetext{
*Correspondence: yshoji@mri-jma.go.jp

${ }^{1}$ Meteorological Research Institute, Japan Meteorological Agency,

Tsukuba, Japan

Full list of author information is available at the end of the article
}

et al. 2004; Benevides et al. 2015; Guerova et al. 2016). The GNSS Earth Observation Network (GEONET) of the Geospatial Information Authority of Japan (GSI) covers the Japanese archipelago with more than 1300 GNSS antennas and is used as a precise crustal deformation monitoring network. Even though the primary purpose of GEONET is crustal deformation monitoring, it is a reliable source of PWV on the ground, so the Japan Meteorological Agency (JMA) started assimilation of the GEONET-derived PWV into their operational numerical weather prediction (NWP) system in 2009 (Ishikawa 2010).

Water vapor plays a crucial role for the development of hazardous cumulus convection. Via the condensation process, moisture releases latent heat which becomes an 
energy source for the rapid development of cumulus convection. Because most of the atmospheric water vapor concentrates in lower troposphere, monitoring of water vapor in low level has received a lot of attention. For the island country such as Japan, low-level moisture often comes from ocean. Several studies of hazardous weather events have revealed that low-level moisture from the ocean plays an essential role in such weather cases (Kato and Aranami 2005; Shoji et al. 2009).

There are several satellite-borne water vapor sensors. Current and future meteorology-related satellite list is maintained by the World Meteorological Organization's space program (WMO 2017). Satellite-based microwave radiometers (e.g., SSM/I) and moderate-resolution imaging spectroradiometer near-infrared channels observe atmospheric water vapor distribution over the ocean. Atmospheric infrared sounder (AIRS) possesses ability to observe vertical water vapor structure. However, such space-borne microwave observations onboard polar orbiters do not provide continuous information, even though the observation density has been increasing year by year. Moreover, microwave observations are highly affected by the conditions of the clouds and the Earth's surface, and researches have been conducted to resolve the issues (e.g., Zhou et al. 2016). Geostationary meteorological satellites (Meteosat, Himawari, GOES) also equipped with water vapor channels to observe water vapor distribution in middle and/or upper troposphere. Currently, there is no continuous water vapor sensor which can observe water vapor amount over the ocean.

Unlike ground-based fixed GNSS stations, ocean platform (ship and buoy) GNSS measurements face difficulties in analyzing the variable antenna position simultaneously with the atmospheric delay. However, several studies have been addressing this problem. Chadwell and Bock (2001) used a buoy-based GPS receiver to estimate the PWV compared to that obtained by nearby (within $10 \mathrm{~km}$ ) radiosonde and ground fixed GPS stations and obtained root mean square (RMS) agreements of 1.5 and $1.8 \mathrm{~mm}$, respectively. Rocken et al. (2005) installed two GPS antennas near the front mast of a 138,000-ton ship and executed two 1-week observation experiments. They compared PWV retrieved from GPS measurements and that obtained from a radiosonde observations and from a water vapor radiometer (WVR) measurements, and obtained good agreements (less than $2 \mathrm{~mm}$ RMS to radiosonde and at $2.8 \mathrm{~mm}$ RMS to the WVR). Fujita et al. (2008) introduced a choke ring-type GPS antenna on the 8678-ton research vessel MIRAI, analyzed PWV, and compared with more than 300 radiosonde observations in the equatorial Indian Ocean. The RMS was $2.27 \mathrm{~mm}$ and the mean difference was less than $1 \mathrm{~mm}$ at night. Boniface et al. (2012) compared PWV over the Mediterranean Sea determined from the shipborne GPS, numerical weather prediction (NWP) model outputs, and MODIS retrieval. They found that most of the observation period, GPS and NWP outputs showed good agreement. They also discussed the possible cause of disagreements in two cases when large offsets occurred and attributed to NWP's excursions during transition between local Mediterranean weather conditions. Currently, beside GPS, the GNSS includes several satellite navigation systems (e.g., Russian GLONASS, Japanese Quasi-Zenith Satellite System (QZSS)). Increased number of navigation satellites by utilizing multiple GNSSs resulted in higher accuracy of ocean platform GNSS water vapor measurements. Fujita et al. (2014) conducted PWV retrieval experiment using a multi-GNSS receiver installed on the 3991-ton research vessel HAKUHO MARU. Using GPS, GLONASS, and QZSS together for their PWV analysis resulted in much better agreement with radiosonde observations Shi-Jie et al. (2016) equipped a GPS receiver on a lightweight (300-ton) experimental ship, conducted GPS observations in the Chinese Bohai Sea, and compared the GPS-derived PWV and slant-path water vapor to that derived from the Fifth-Generation NCAR/Penn State Mesoscale Model (MM5). The RMS agreements were $1.5 \mathrm{~mm}$ and $3.9 \mathrm{~mm}$, respectively.

The above-mentioned previous studies are post-analysis with used final precise ephemerides or rapid ephemerides. Recently, real-time GNSS analysis technology has remarkably been improving. For example, on April 1, 2013, the International GNSS Service began official providing of real-time orbit and clock corrections. In September 2014, the Japan Aerospace Exploration Agency (JAXA) started real-time service of providing ephemerides produced with a Multi-GNSS orbit and clock estimator called MADOCA (Multi-GNSS Advanced Demonstration tool for Orbit and Clock Analysis) (Takasu 2013). Shoji et al. (2016) conducted four shipborne (three research vessels and one passenger ferry) GNSS observations to evaluate the performance of the real-time ephemerides over the ocean. The MADOCA real-time ephemerides were applied to a kinematic precise point positioning (PPP) (Zumberge et al. 1997) procedure to find that the analyzed PWV time series was contaminated with occasionally occurring unrealistic sharp variations. The characteristics of the spiky variations (e.g., periodic occurrence with a cycle of one sidereal day, largely varying post-fit phase residuals distribution) insisted large negative impact of the reflected signals (the multi-path effect). In their study, a simple quality control (QC) procedure based on the amount of PWV time variation was introduced. As a result, the retrieved PWVs had 3.4-5.4 mm RMS differences compared to the radiosonde observations and $2.3-3.7 \mathrm{~mm}$ RMS to those analyzed at nearby fixed ground GNSS 
sites. However, more than $60 \%$ of the retrieved PWV was rejected through the $\mathrm{QC}$ process on the research vessels, while $6-11 \%$ was rejected on the passenger ferry. The results imply a larger multi-path effect on the research vessels, where the GNSS antennas are surrounded by machines and equipment. However, there is a possibility that different vessel size (Passenger ferry was 16,187 ton and $162 \mathrm{~m}$ length, while research vessels were 1380-1629 ton and 66-82 $\mathrm{m}$ length.) The passenger ferry was about ten times heavier and size was about two times larger than research vessels. It is said that the pitching of a ship is smaller on the longer ship.

The purpose of this study is to prove multi-path is the cause of frequent occurrence of outliers in the research vessels. Also, in order to understand current performance and applicable limitations, we need to further investigate the error sources in retrieved PWV from shipborne GNSS observations. To examine the causes of the errors, we set two GNSS antennas at different locations on a research vessel, RYOFU MARU, which is one of the three research vessels used in the experiment of Shoji et al. (2016). One GNSS antenna was set upped near the Shoji et al. (2016), and another antenna was installed on top of the mast. PWVs obtained from two GNSS measurements are compared with the radiosonde observations launched from the RYOFU MARU. Then, differences in GNSS PWV against radiosonde are compared with the amount of PWV, estimated GNSS antenna altitude, the relative wind speed, the significant wave height, the cruising speed, and the water vapor profiles. The outline of this paper is as follows. In the next section, we outline the observation and analysis procedures. Next, we show the results of the comparison with the radiosonde observations. Finally, we discuss the error in the GNSS PWV and describe the conclusions of the study.

\section{Observation, data processing, and quality control Observation}

The vessel we used in this study is JMA's research vessel the RYOFU MARU, one of the vessels used in the study of Shoji et al. (2016). Figure 1 shows the locations of the two GNSS antennas on the vessel. A Trimble Zephyr II antenna connected to a Trimble NetR9 receiver was installed on the vessel radar mast (MAST), and a JAVAD GrAnt-G3T antenna was connected to a GNSS Technologies Inc. START-GS receiver on the left side of the upper deck (DECK). Here, "MAST" and "DECK" are abbreviations to briefly distinguish each multi-path environment feature in this RYOFU MARU experiment. The multipath environment is specific to each vessel. The antennareceiver pair of DECK was also used for the RYOFU MARU observations of Shoji et al. (2016); however, the location was moved $4 \mathrm{~m}$ backward to increase the distance from the radar mast, which is regarded as one of the major multi-path sources. Because the observation systems of MAST and DECK are different, after the main experimental observation period (October 19, 2016-June 19, 2017), we relocated the MAST antenna to the DECK position and conducted additional observations from June 19 to August 6, 2017. We call this additional observation DECKt. All receivers observed GPS, GLONASS, and QZSS. Sampling interval and elevation cutoff angle were set as $1 \mathrm{~Hz}$ and zero degrees, respectively.

The RYOFU MARU is equipped with meteorological sensors, a radiosonde observation facility, and a microwave-type wave height meter (WM-2 developed by Tsurumi-Seiki Co., Ltd.). Table 1 summarizes the size and weight of the vessel and the height of the meteorological sensors and the GNSS antennas. WM-2 is an apparatus with an acceleration sensor and a microwave Doppler radar. The microwave Doppler radar measures the vessel's relative height against the sea surface at the bow, while the acceleration sensor estimates the vertical motion at the bow. The RYOFU MARU logs the $2 \mathrm{~Hz}$ sampled bow height and observed wave height. The actual wave height is calculated by subtracting the vertical displacement at the bow from the observed bow height from the sea surface measured by the microwave Doppler radar. The significant wave height is calculated twice an hour using 20 -min consecutive observations from 5 to $25 \mathrm{~min}$ and from 35 to $55 \mathrm{~min}$ by averaging the wave height of the highest third of the actual wave heights.

\section{Data processing}

As listed in Table 2, the GNSS analysis procedure for this study follows Shoji et al. (2016) except for elevation cutoff angle. Shoji et al. (2016) used $5^{\circ}$ as elevation cutoff angle. In this study, following Fujita et al. (2008) and Boniface et al. (2012), we set 3 degree as elevation cutoff angle. We processed the GNSS analyses for the shipborne observations using RNX2RTKP, a command-line application for post-GNSS processing of RTKLIB version 2.4.2 (Takasu 2013). We adopted the kinematic PPP method to estimate the coordinates, zenith wet delays (ZWDs) and zenith hydrostatic delay (ZHD) every second. The static PPP method was applied for a GEONET station (3023, Chiba Ichikawa), and 1-day averaged coordinates with every 30-s ZWDs were analyzed. The followings are the main analysis options which were set for both the shipborne and GEONET analyses:

1. A three-degree cutoff elevation angle;

2. The global mapping function (Boehm et al. 2006);

3. The ZWD was regarded as a random-walk variable with a process noise of $0.1 \mathrm{~mm} / \mathrm{s}^{1 / 2}$ (RTKLIB's default value); and 
4. The ZHD was estimated using the geodetic height above sea level as

$$
\begin{aligned}
& \mathrm{ZHD}=0.002277 \times P \\
& P=1013.25 \times\left(1-2.2557 \times 10^{-5} h\right)^{5.2568},
\end{aligned}
$$

where $P$ and $h$ are the atmospheric pressure at the GNSS antenna and the height above sea level, respectively.

Precise orbit and clock information are required in the PPP procedure. We tested the MADOCA real-time product provided by JAXA. The goal for the MADOCA real-time orbit and clock accuracy is $6 \mathrm{~cm}$ and $0.1 \mathrm{~ns}$, respectively, for GPS and $9 \mathrm{~cm}$ and $0.25 \mathrm{~ns}$, respectively, for GLONASS and QZSS. To enhance system redundancy, there are two streams, MDC1 and 2, in MADOCA. In the experiment of Shoji et al. (2016), MDC2 showed a slightly better performance than MDC1. In this study, we used MDC2 for the GNSS analysis. JAXA also provides MADOCA final products (JXF) (orbit; every $5 \mathrm{~min}$, clock; every $30 \mathrm{~s}$ ) via the Internet (ftp://mgmds01.tksc.jaxa.jp/products/). We compare the retrieved PWVs using JXF and MDC2 at the last paragraph of this section.

Atmospheric pressure and temperature are needed to calculate the PWV from the zenith tropospheric delay (ZTD) (Bevis et al. 1992). The RYOFU MARU is equipped with surface meteorological sensors and observes the pressure, temperature, humidity, wind direction, and speed. We used a 1-min interval dataset provided by the JMA.

The temperature and atmospheric pressure at the GNSS antenna are estimated using the hydrostatic equilibrium:

$$
\begin{aligned}
& P_{\mathrm{GNSS}}=P_{\text {baro }}\left(\frac{T_{\text {baro }}-\Gamma \times\left(Z_{\mathrm{GNSS}}-Z_{\text {baro }}\right)}{T_{\text {baro }}}\right)^{\frac{g}{R_{d}} \Gamma}, \\
& T_{\text {baro }}=\Gamma \times\left(Z_{\text {baro }}-Z_{\text {thermo }}\right),
\end{aligned}
$$

where $P_{\text {baro }}$ and $P_{\mathrm{GNSS}}$ are the atmospheric pressures observed by the barometer and the estimated value at the GNSS antenna, respectively, $T_{\text {thermo }}$ and $T_{\text {baro }}$ are the temperatures observed by the thermometer and the estimated value at the barometer, respectively, $Z_{\mathrm{GNSS}}$ and $Z_{\mathrm{baro}}$ are the

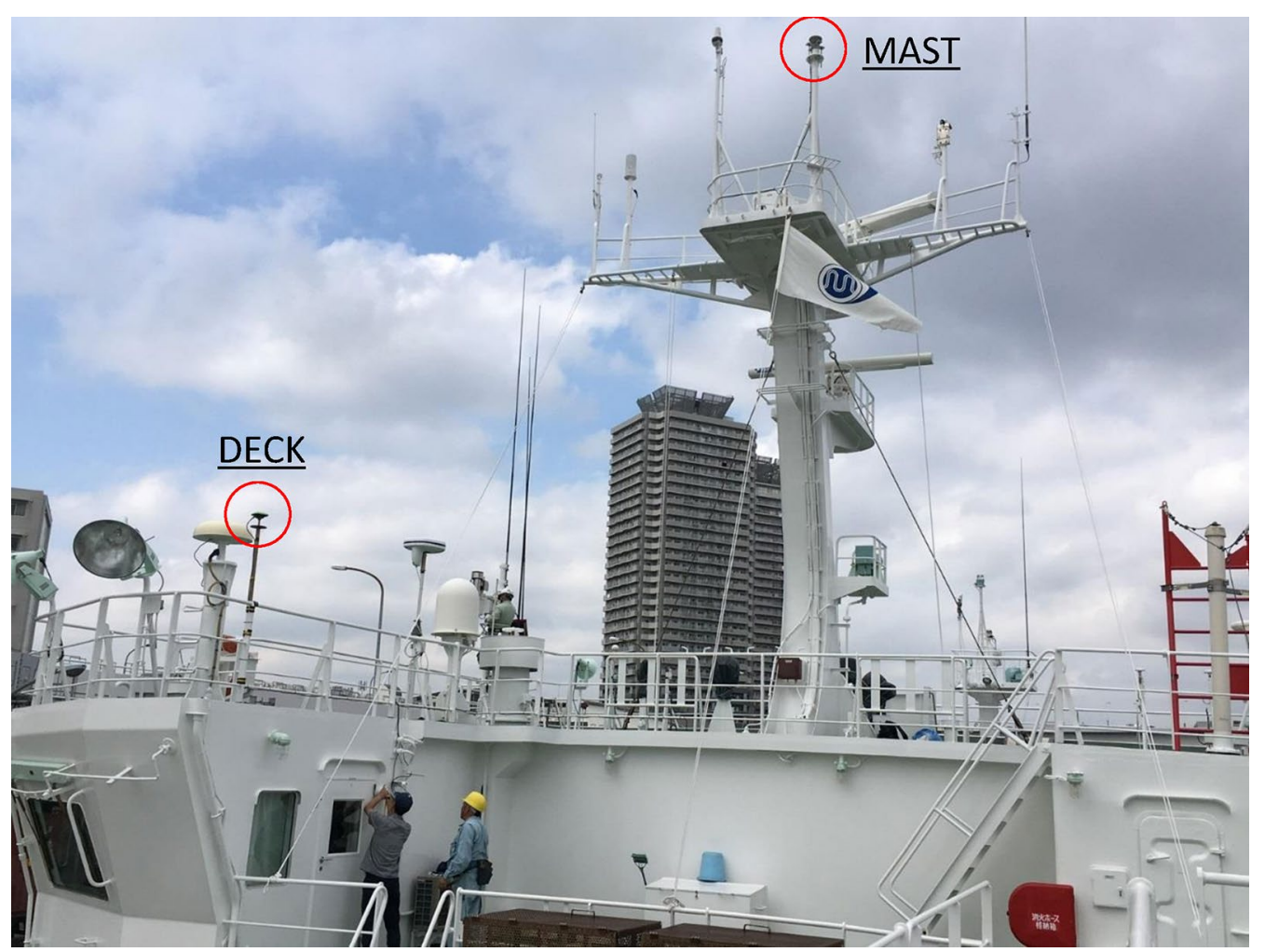

Fig. 1 GNSS antennas installed on the top deck (DECK) and on the mast (MAST) of the RYOFU MARU on October 19, 2017. The MAST antenna was moved to the DECK location on June 19, 2017, and was used for additional observations as DECKt until August 6, 2017 
Table 1 Weights and sizes of the RYOFU MARU, the height of the meteorological sensors, and the specifications of the GNSS observations

\begin{tabular}{|c|c|c|c|c|}
\hline \multicolumn{2}{|c|}{ Vessel weight and size } & \multirow{2}{*}{$\begin{array}{l}\text { Gross tonnage } \\
1380 \mathrm{t}\end{array}$} & \multirow{2}{*}{$\begin{array}{l}\text { Length } \\
82.0 \mathrm{~m}\end{array}$} & \multirow{2}{*}{$\begin{array}{l}\text { Breadth } \\
13.0 \mathrm{~m}\end{array}$} \\
\hline & & & & \\
\hline \multirow{2}{*}{\multicolumn{2}{|c|}{$\begin{array}{l}\text { Height of the meteorological } \\
\text { sensors (above sea level) }\end{array}$}} & Barometer & Thermometer & Radiosonde base \\
\hline & & $2.8 \mathrm{~m}$ & $13.3 \mathrm{~m}$ & $8.0 \mathrm{~m}$ \\
\hline \multirow[t]{5}{*}{ GNSS } & Abbreviation & MAST & DECK & DECKt \\
\hline & Antenna & Zephyr 2 (Trimble) & GrAnt-G3T (JAVAD) & Zephyr 2 (Trimble) \\
\hline & Receiver & NetR9 (Trimble) & $\begin{array}{l}\text { START-GS (GNSS } \\
\text { Technologies Inc.) }\end{array}$ & NetR9 (Trimble) \\
\hline & Antenna height above sea level & $20.7 \mathrm{~m}$ & $13.8 \mathrm{~m}$ & $13.8 \mathrm{~m}$ \\
\hline & Duration & \multicolumn{2}{|c|}{$\begin{array}{l}\text { 2016/10/19-2017/03/09 } \\
2017 / 04 / 25-2017 / 06 / 19\end{array}$} & 2017/06/19-2017/08/06 \\
\hline
\end{tabular}

heights of the GNSS antenna and thermometer, respectively, and $\mathrm{g}, R_{d}$, and $\Gamma$ are the gravitational acceleration, the specific gas constant for dry air, and the temperature laps rate, respectively. In this study, we use $\Gamma=0.0065 \mathrm{~K} / \mathrm{m}$.

Figure 2 compares the time series of the PWV retrieved on the RYOFU MARU (c, d) and at a nearby GEONET station 3023 (Chiba Ichikawa) (a, b) from December 3, 2016, to December 5, 2016. During this period, the RYOFU
MARU was located at its homeport (Daiba, Minato Ward, Tokyo) and the sea surface was calm (wave height was less than $0.4 \mathrm{~m}$ ) during the period. Figure $2 \mathrm{a}$ and $\mathrm{b}$ compares the results from static PPP and kinematic PPP for a fixed GNSS station. JXF is applied for Fig. 2a, while MDC2 is applied for Fig. 2b. In Fig. 2a, even at the fixed station, we see several millimeter PWV differences between static and kinematic procedures. In Fig. 2b, as a result of applying

Table 2 Main specifications of the GNSS analysis

\begin{tabular}{|c|c|c|}
\hline Classification & Specification & Remarks \\
\hline Software & RNX2RTKP (RTKLIB ver. 2.4.2, patch 12) & \\
\hline \multirow[t]{3}{*}{ Analysis procedure } & Precise point positioning & \\
\hline & Kinematic (Shipborne GNSS) & \\
\hline & Static (GEONET station) & \\
\hline Integer ambiguity & Not fixed (no PPP-AR applied) & \\
\hline Ephemeris & MADOCA real-time product (MDC2) & https://ssl.tksc.jaxa.jp/madoca/public/public_index_en.html \\
\hline Mapping function & GMF (no gradient estimation) & Boehm et al. (2006) \\
\hline Elevation cutoff angle & $3^{\circ}$ & \\
\hline Antenna phase center variation & $\begin{array}{l}\text { IGS08_1793.atx MAST (DECKt): "TRM55970. } 00 \\
\text { NONE"DECK:"JAV_GRANT-G3T NONE" }\end{array}$ & http://ftp.igs.org/pub/station/general/igs08.atx \\
\hline Geoid model & $\begin{array}{l}\text { EGM2008-SE }\left(1{ }^{\prime \prime}\right)(\text { Und } \min 1 \times 1 \text { egm2008 is } \\
\quad W=82 \text { WGS84 TideFree_SE })\end{array}$ & $\begin{array}{l}\text { http://earth-info.nga.mil/GandG/wgs84/gravitymod/ } \\
\text { egm2008/egm08_wgs84.html }\end{array}$ \\
\hline Tidal effect & $\begin{array}{l}\text { Solid earth tide: IERS Conventions } 2010 \text { Ocean } \\
\text { Tidal Loading: Not applied }\end{array}$ & $\begin{array}{l}\text { Petit and Luzum (2010) IERS Technical Note No.36, IERS Con- } \\
\text { ventions (2010) }\end{array}$ \\
\hline lonosphere correction & lonosphere-free linear combination & \\
\hline \multirow[t]{2}{*}{ ZHD } & $\mathrm{ZHD}=0.002277 \times P$ & Elgered et al. (1991) \\
\hline & $\begin{array}{l}P=1013.25 \times(1-2.2557 \times 10-5 / h)^{5.2568} P \text { : } \\
\text { atmospheric pressure }(\mathrm{hPa}), h \text { : geodetic height } \\
\text { above mean sea level }\end{array}$ & \\
\hline \multirow[t]{3}{*}{ Time-dependent parameters } & Antenna coordinate & Updated every $1 \mathrm{~s}$ \\
\hline & Receiver clock & \\
\hline & $\begin{array}{l}\text { ZWD random-walk variable with process noise of } \\
0.1 \mathrm{~mm} / \mathrm{s}^{1 / 2}\end{array}$ & \\
\hline
\end{tabular}


less precise real-time ephemeris, fluctuations in PWV time sequence with a cycle of approximately several hours emerge and this fluctuation is more conspicuous in kinematic analysis with real-time ephemeris. The same characteristics can be seen for RYOFU MARU antennas (Fig. 2c, d). Several unrealistic spiky time variations are seen in DECK results regardless of ephemerides. We can summarize the results shown in Fig. 2 as follows.

1. Accuracy of ephemeris affects that of retrieved GNSS PWV, especially in kinematic PPP procedure.

2. In order to remove unrealistic spiky PWV time variation from meteorological use, certain quality control procedure is indispensable.

In the next section, we describe a simple quality control procedure in this study.

\section{Quality control}

The panels in Fig. 3 are sky maps of the post-fit phase residuals averaged over 16 days when the vessel was anchored at its home port Daiba. Large values are sporadically distributed in the sky maps of DECK, indicating a large multi-path influence. Comparatively, the sky map of MAST shows much smaller variations, indicating a smaller multi-path influence.

According to a theoretical consideration of the possible PWV time variation in $1 \mathrm{~min}$ and the statistical result of the GNSS PWV time variation, Shoji et al. (2016) set a 1-mm per minute PWV variation as the threshold for outliers. In this study, we follow Shoji et al. (2016) but adopt the ZTD time variation for the QC procedure because we estimated the ZTD every $1 \mathrm{~s}$ and the outliers tended to occur suddenly. Applying the ZTD 1-s time variation as the outlier detector, we likely found outliers slightly faster than when using the 1-min time variation
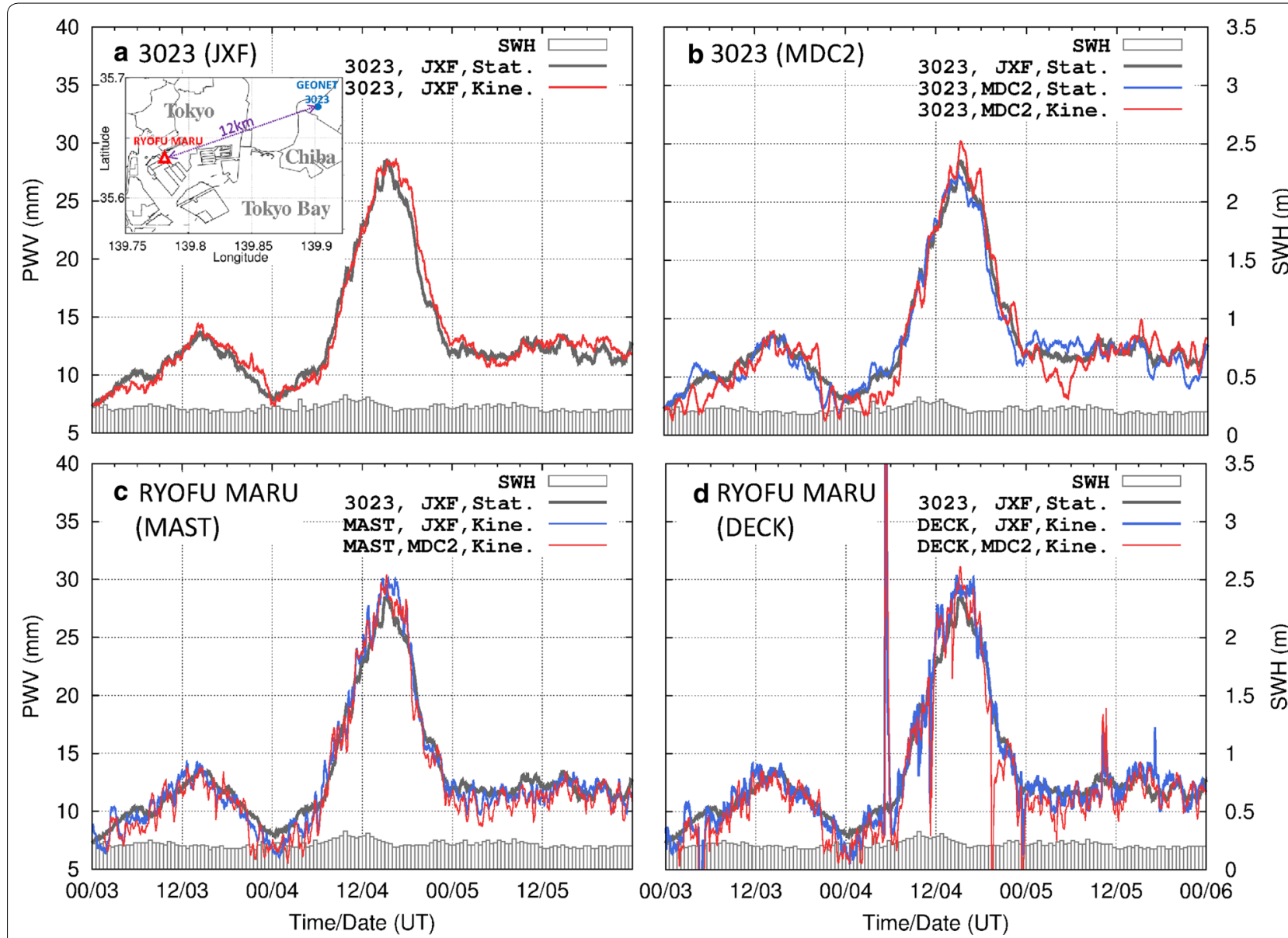

Fig. 2 Comparison of GNSS PWVs estimated at RYOFU MARU (c, d) and nearby GEONET station (a, b) for the 3 days from December 3, 2016, to December 5, 2016. The GEONET station 3023 (Chiba Ichikawa) locates approximately 12 km ENE from the RYOFU MARU. Results obtained using a final ephemeris (JXF) and a real-time ephemeris (MDC2) are compared. Both static and kinematic PPP procedures are conducted for GEONET station 3023, while only kinematic PPP is executed for RYOFU MARU stations. During this period, the RYOFU MARU was anchored at its home port (Daiba, Minato Ward, Tokyo). The gray boxes indicate the significant wave height observed by the RYOFU MARU (right axis) 


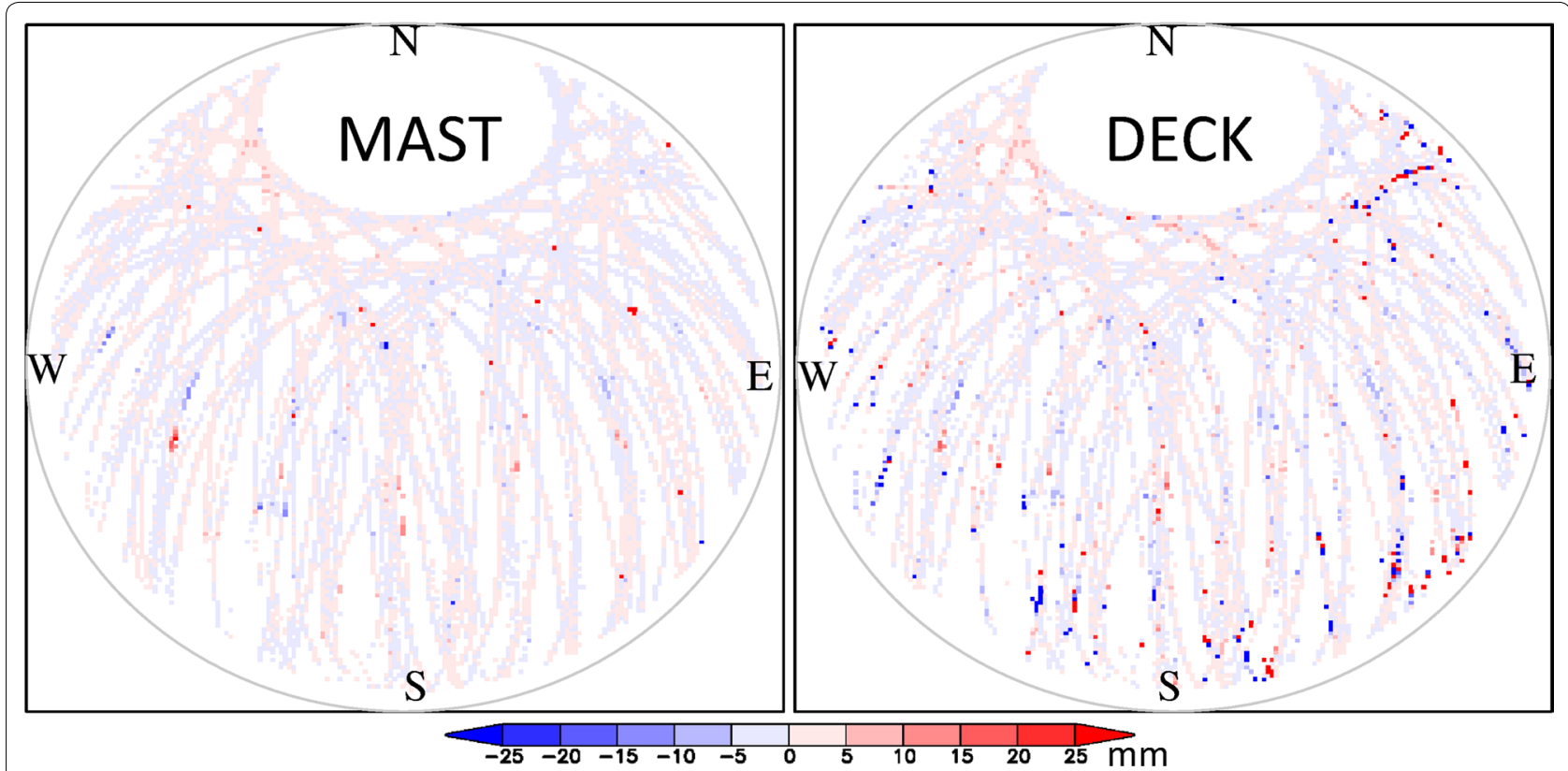

Fig. 3 Sky plots of the time-averaged post-fit phase residual of the averaged L3 ionosphere-free linear combination, while the RYOFU MARU was anchored at its home port (Daiba, Tokyo)

of the PWV. According to Shoji et al. (2016), the accumulated frequency of the less than $1-\mathrm{mm} / \mathrm{min}$ PWV variation was more than $99.5 \%$. In this study, according to the statistical ZTD time variation frequency analysis shown in Fig. 4, we set a $0.1-\mathrm{mm} / \mathrm{s}$ ZTD variation as the threshold of the outliers. Figure 4 shows the frequency and accumulated frequency of the 1-s ZTD time variation of DECK, MAST, and DECKt. Because MAST and DECKt use the same antenna and receiver pair, the larger frequency of more than $0.1-\mathrm{mm} / \mathrm{s}$ ZTD time variations of DECK and DECKt implies a larger multi-path effect on the deck. The retrieved PWV was rejected as erroneous if the value met one of the following conditions:

1. Any of the ZTD time variations exceeded $0.1 \mathrm{~mm} / \mathrm{s}$ within the previous hour;

2. The PWV value was less than or equal to $0 \mathrm{~mm}$; or

3. The PWV value was greater than or equal to $90 \mathrm{~mm}$.

The data rejection rate (the number of rejected data divided by the total number of pairs) gives the quality of GNSS observations and the retrieved PWV.

\section{Results of comparison with radiosonde observations}

A radiosonde launching facility is equipped with the RYOFU MARU and upper air observations over the ocean are conducted. Through this study, the VAISALA RS92-SGP radiosonde was used. The GNSS antennas were set higher than the radiosonde base. Therefore, as

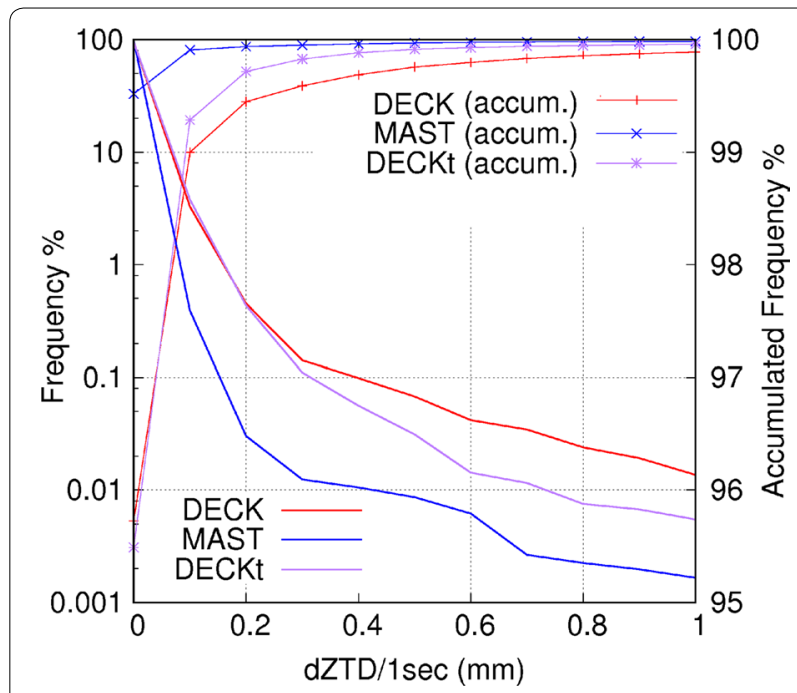

Fig. 4 Frequency distribution of the $1 \mathrm{~s}$ ZTD variation obtained from the shipborne GNSS observations. The lines indicate the frequency of each bin divided by a 0.1-mm interval (left axis). The lines with points indicate the accumulated frequency (right axis)

a height correction, the radiosonde observed water vapor amount between the radiosonde launching point to the GNSS antenna was removed from radiosonde observations. Figure 5 shows the GNSS PWV retrieved from the MAST observation and its difference from radiosonde observation plotted on the two-dimensional map along the RYOFU MARU trajectory, and Fig. 6 shows those plotted as time series. A total of 77 radiosondes were 


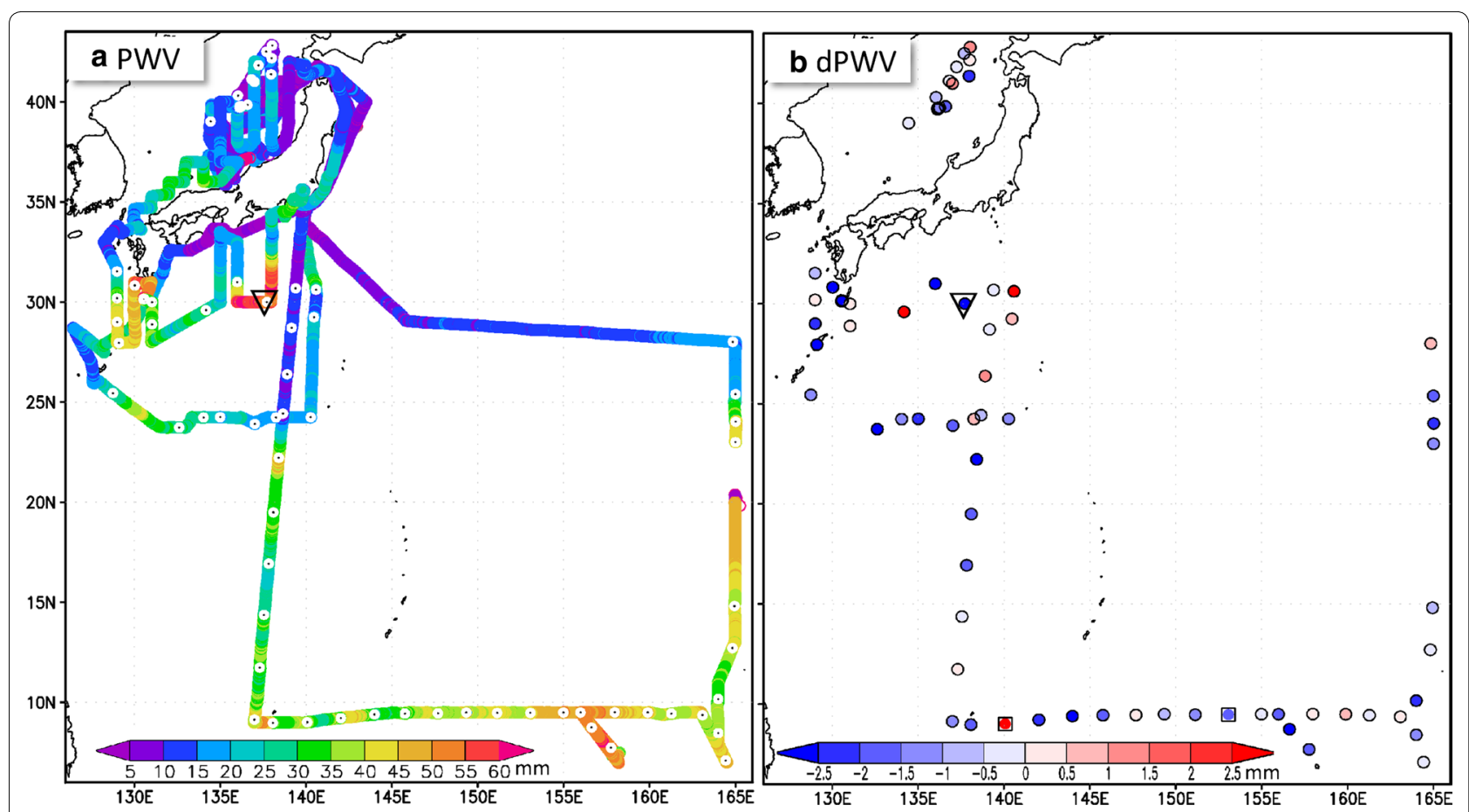

Fig. 5 a Estimated GNSS PWV from the MAST measurements along the RYOFU MARU trajectory. White circles represent the radiosonde launch locations. b Distribution of differences of GNSS PWV against radiosonde. Rejected data through the quality control are surrounded by black squares. An inverted triangle in each (a) and (b) indicates the area where a radiosonde launched at 2331UTC on June 10, 2017

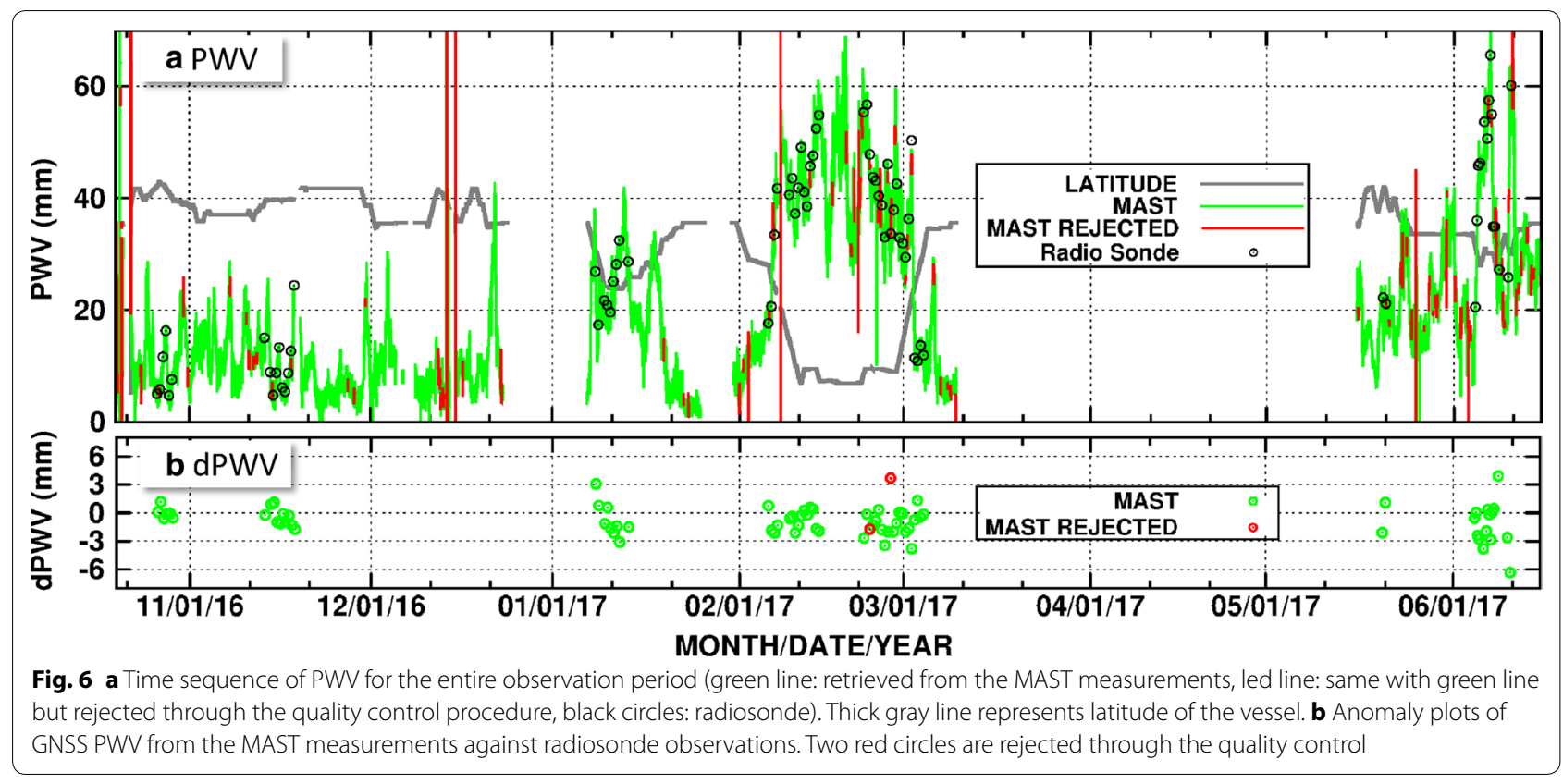

launched during the campaign. The launch locations are plotted with white circles in Fig. 5a. From Figs. 5 and 6, we can recognize that most of the differences are within $3 \mathrm{~mm}$. Neither distinct geographical feature nor seasonal feature is recognized.
Figure 7 shows a comparison of the results of the GNSS PWV with the radiosonde observations. If radiosonde rises with a mean ascent rate of $5 \mathrm{~m} / \mathrm{s}$ as Mateus et al. (2015) notes, it takes approximately half an hour for the radiosonde to travel up through the troposphere 

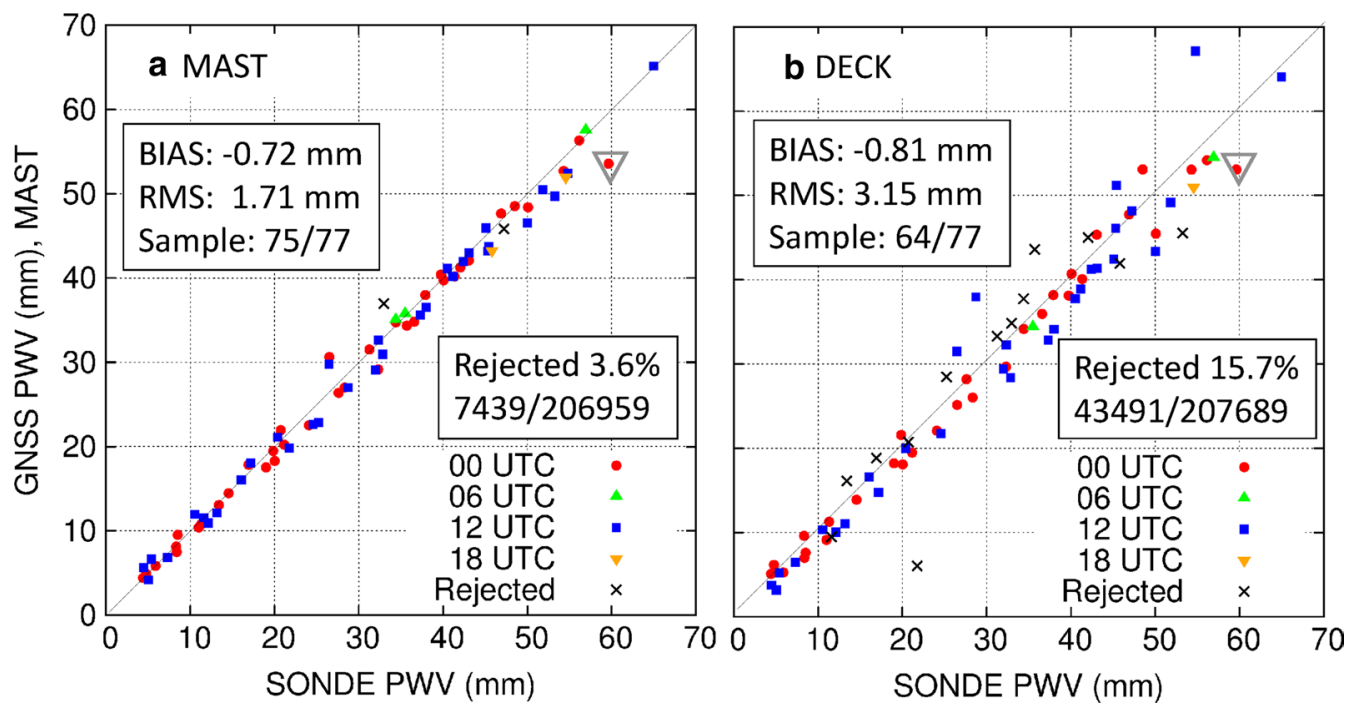

Fig. 7 Scatter diagrams of the differences in the GNSS PWV obtained from the MAST measurements versus the radiosonde observations. The red circle plot with the gray inverted triangle is a comparison with the radiosonde launched at 2331 UTC on June 10, 2017. The cause of the large difference is discussed in "Discussion and Summary"

where most of the water vapor exists. Therefore, the GNSS PWVs were time-averaged over $30 \mathrm{~min}$ beginning at each radiosonde launch time. The fact that the agreement of MAST (bias: $-0.72 \mathrm{~mm}$, RMS: $1.71 \mathrm{~mm}$, rejected rate: $3.6 \%$ ) is much better than that of DECK (bias: $-0.81 \mathrm{~mm}$, RMS: $3.15 \mathrm{~mm}$, rejected rate: $15.7 \%$ ) implies a larger multi-path effect on the DECK observations. From now on, we focus on the results of the MAST.

Figure 8 shows the relationship between the GNSS PWV differences and the radiosonde observed PWV. The GNSS PWV tends to be smaller than the radiosonde observations and the negative tendency increases with the PWV value. As previous studies have indicated (e.g., Beutler et al. 1998; Shoji et al. 2000), the error in the GNSS estimated vertical coordinate and the error in the GNSS PWV have a positive correlation. Figure 9 shows the certain relationship between the estimated vertical coordinate of the GNSS antenna and differences in the GNSS PWV. Of course, we don't have any evidence of the possibility of vertical coordinate error. There are several mechanisms which cause sea surface height changes, e.g., tidal effects, atmospheric pressure, and seawater density. The GNSS antenna altitude may reflect the actual ocean surface height. At least, the results shown in Figs. 8 and 9 indicate the need to closely evaluate the accuracy of the GNSS antenna altitude.

In addition to the error in estimated altitude there are several possible causes of the GNSS PWV error. In the next section, we discuss several possible causes associated with the kinematic PPP analysis.

\section{Discussion and summary}

In this section, we discuss several possible sources of errors in the shipboard GNSS positioning and troposphere estimation.

First, we discuss the largest difference case, which recorded in the comparison between radiosonde launched at 2331 UTC on June 10, 2017. Figure 10 shows profiles of the refractivity and relative humidity observed by the radiosonde. Here the refractivity is calculated according to the following equation using the radiosonde observed pressure, humidity and temperature:

$$
N=k_{1}\left(\frac{P_{d}}{T}\right)+k_{2}\left(\frac{P_{v}}{T}\right)+k_{3}\left(\frac{P_{v}}{T^{2}}\right),
$$

where $T, P_{d}$, and $P_{v}$ are the temperature, dry pressure, and vapor pressure, respectively, and $k_{1}, k_{2}$, and $k_{3}$ are constants. We follow Boudouris (1963) and set $k_{1}=77.6$, $k_{2}=71.98$, and $k_{3}=375,400 \mathrm{~K}^{2} / \mathrm{hPa}$.

Refractivity inversion up to approximately $400 \mathrm{~m}$ is seen. There was no inversion for the dry part [the first term on the right-hand side of Eq. (5), the blue line in Fig. 10] of the refractivity. The inversion was caused by water vapor. Around this time, the RYOFU MARU was under a precipitation system. A total of $4.5 \mathrm{~mm}$ of precipitation was recorded in the $30 \mathrm{~min}$ from 2331 UTC on June 10 to 0000 UTC on June 11. The cruising speed was approximately $7.0 \mathrm{~m} / \mathrm{s}$, the relative wind speed was $12.6-13.2 \mathrm{~m} / \mathrm{s}$, and the significant wave height was $0.9 \mathrm{~m}$. $\mathrm{Li}$ et al. (2010) studied the effect of radio wave propagation under ducting environment and found great effects 


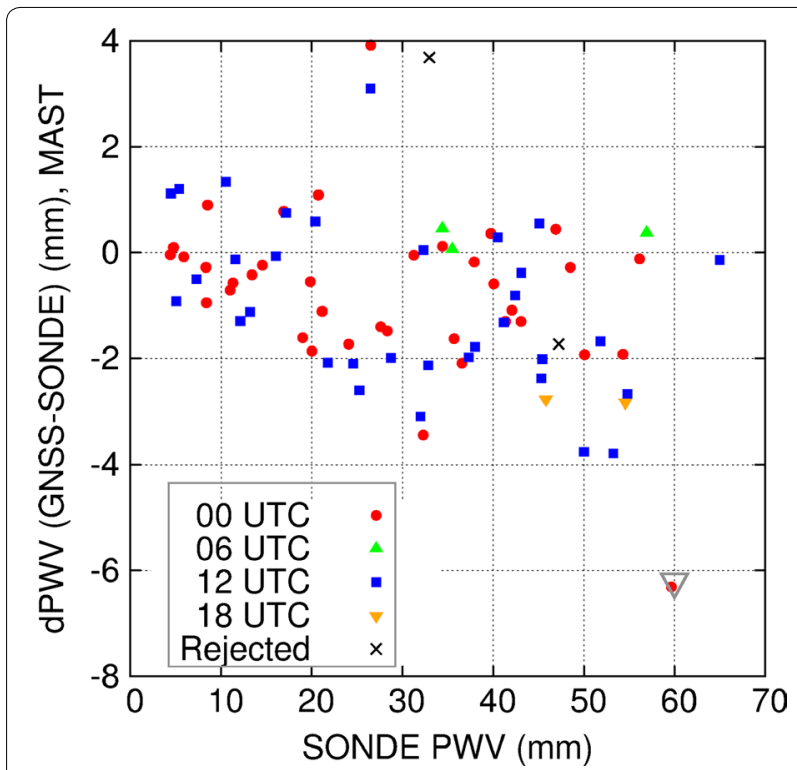

Fig. 8 Scatter diagrams of the differences in the GNSS ZD (ZHD and ZWD) obtained from the MAST measurements versus those estimated from the radiosonde observations. Plots with gray inverted triangles are a comparison with the radiosonde launched at 2331 UTC on June 10,2017. The cause of the large difference is discussed in "Discussion and Summary"

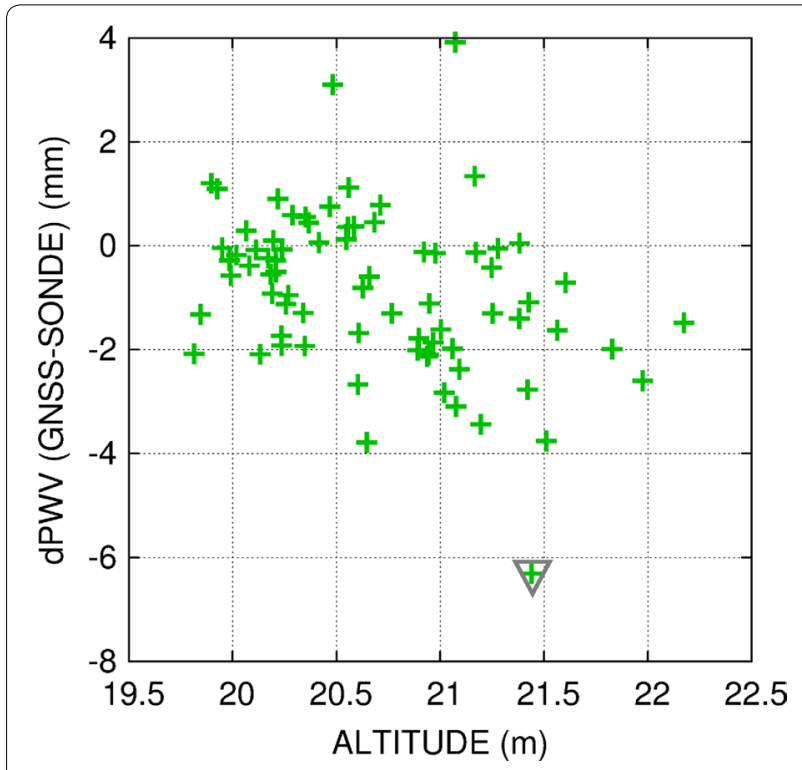

Fig. 9 Scatter plots of the differences in the GNSS PWV versus the radiosonde observations and estimated GNSS antenna (MAST) altitudes. Plots with gray inverted triangles are a comparison with the radiosonde launched at 2331 UTC on June 10, 2017

on GNSS observation, such as longer transform of microwave, formation of shadow zone, and reflect signal propagation loss. A vertical inversion layer caused by water

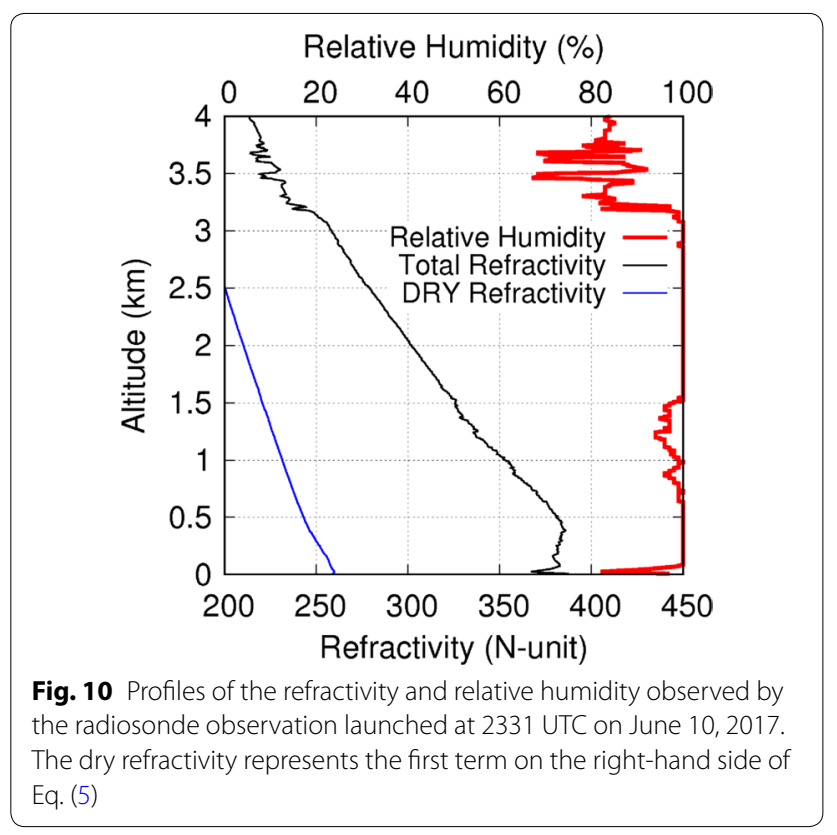

vapor causes surface ducting and might lead to the large negative bias in the GNSS PWV. Figure 11 represents the frequency of the refractivity inversion layer top height observed by the RYOFU MARU radiosonde during the period of six years from 2012 to 2017. The inversion top height is defined as the height at which maximum refractivity was observed from each radiosonde profile. Only two cases observe more than a 300-m inversion height out of 612 launches. Even though the frequency is small, this fact suggests that we should carefully investigate the atmospheric profile, especially the existence of an inversion layer.

In kinematic PPP, the antenna moving speed, direction, and their time variations might cause errors for both the positioning and atmospheric parameter estimations. In addition, dynamic pressure caused by strong wind might cause errors in the atmospheric pressure observation which leads to errors in ZHD estimation. Using wave height measurements and the meteorological observation data of the RYOFU MARU, we compared the PWV differences with the wave height, vessel speed, and wind speed relative to the vessel. As shown in Fig. 12, the correlation is not clear for vessel moving speed and relative wind speed. There seems a certain tendency of higher positive biases under higher significant wave height. Figure 13 shows significant wave heights along the RYOFU MARU trajectory. The white crosses represent the locations where the MAST data are rejected using the quality check procedure in this study. The relation between wave height and GNSS PWV error is not so clear, but, at least, we can conclude that spiky outliers are not caused by 


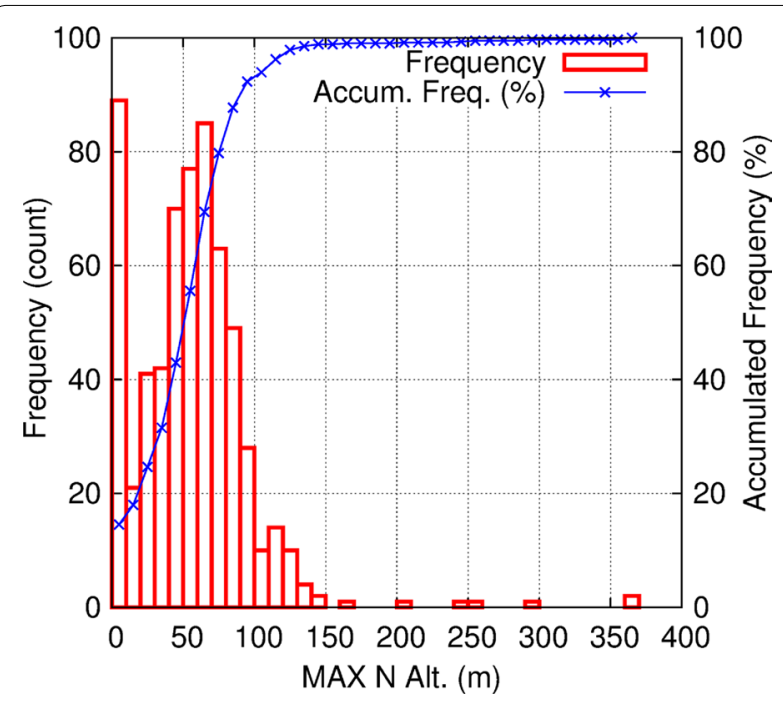

Fig. 11 Frequency of the height of the maximum refractivity of 612 RYOFU MARU radiosonde observations during the period of 2012-2017

the state of sea surface wind. Figure 14 shows the PWV time series estimated from the GNSS measurements and radiosonde during the highest wave period in the campaign (the red rectangle area in Fig. 13). Despite the relatively large waves (SWH 2-7 m), the GNSS PWV appears to agree well with the radiosonde observations. From Figs. 12, 13, 14, we may conclude that SWHs less than $5 \mathrm{~m}$ do not cause large errors in the shipborne GNSS PWV measurements.

The results and discussions in this study can be summarized as follows. (a) The MADOCA real-time orbit has the potential to serve in practical PWV analyses over the ocean in real time (at least with a class of 1300-ton and 80-m-long observation vessels). However, careful consideration of the multi-path effect is essential for shipborne GNSS observations.

Shoji et al. (2016) discussed real-time possibility of shipborne GNSS PWV measurement. However, the results obtained from RYOFU MARU were highly contaminated by outliers and more than $60 \%$ of estimated PWV was rejected. They supposed that multi-path affected the RYOFU MARU GNSS observation. In this paper, by comparing observations on DECK and on MAST on the RYOFU MARU, their hypothesis was confirmed by much smaller rejection rate on less multi-path affected MAST. However, as shown in Fig. 2, GNSS PWV time series by kinematic PPP with real-time ephemeris show fluctuations of several-hour cycle with several-mm amplitude. It may be partly due to analyzing $\mathrm{x}, \mathrm{y}$, and $\mathrm{z}$ coordinates as time-dependent unknown parameters, and partly due to less accuracy of real-time ephemeris compared to final one. Increased number of high-quality observation could bring more stable analysis results. In this study, we used GPS, GLONASS, and QZSS. In the future, inclusion of other GNSS, such as BeiDou and GALILEO, should be investigated.

(b) The effects of the following conditions on the kinematic GNSS measurements are minor, if any:

a relative wind speed of less than $20 \mathrm{~m}$, a cruising speed of less than $8 \mathrm{~m} / \mathrm{s}$ and a significant wave height of less than $5 \mathrm{~m}$.

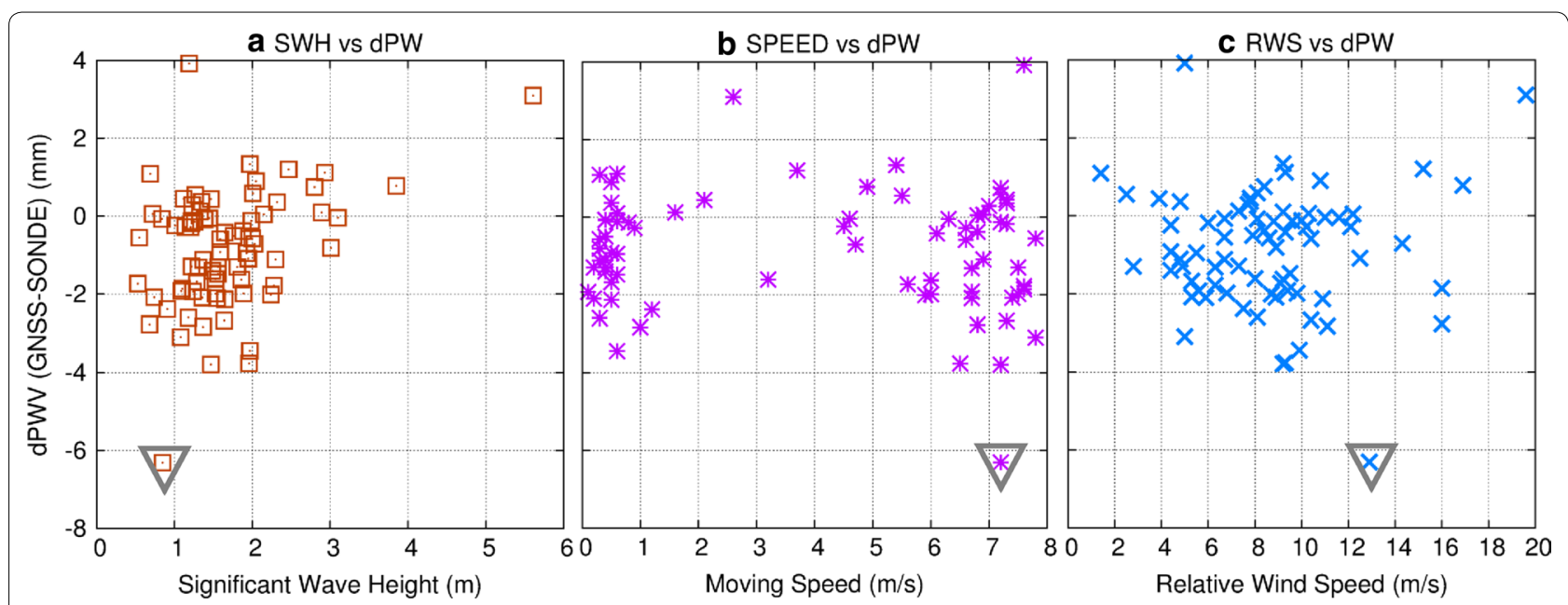

Fig. 12 Scatter plots of the differences in the GNSS PWV versus the radiosonde observations and $\mathbf{a}$ significant wave height, $\mathbf{b}$ vessel moving speed, and $\mathbf{c}$ relative wind speed. Plots with gray inverted triangles are comparisons with the radiosonde launched at 2331 UTC on June 10, 2017 

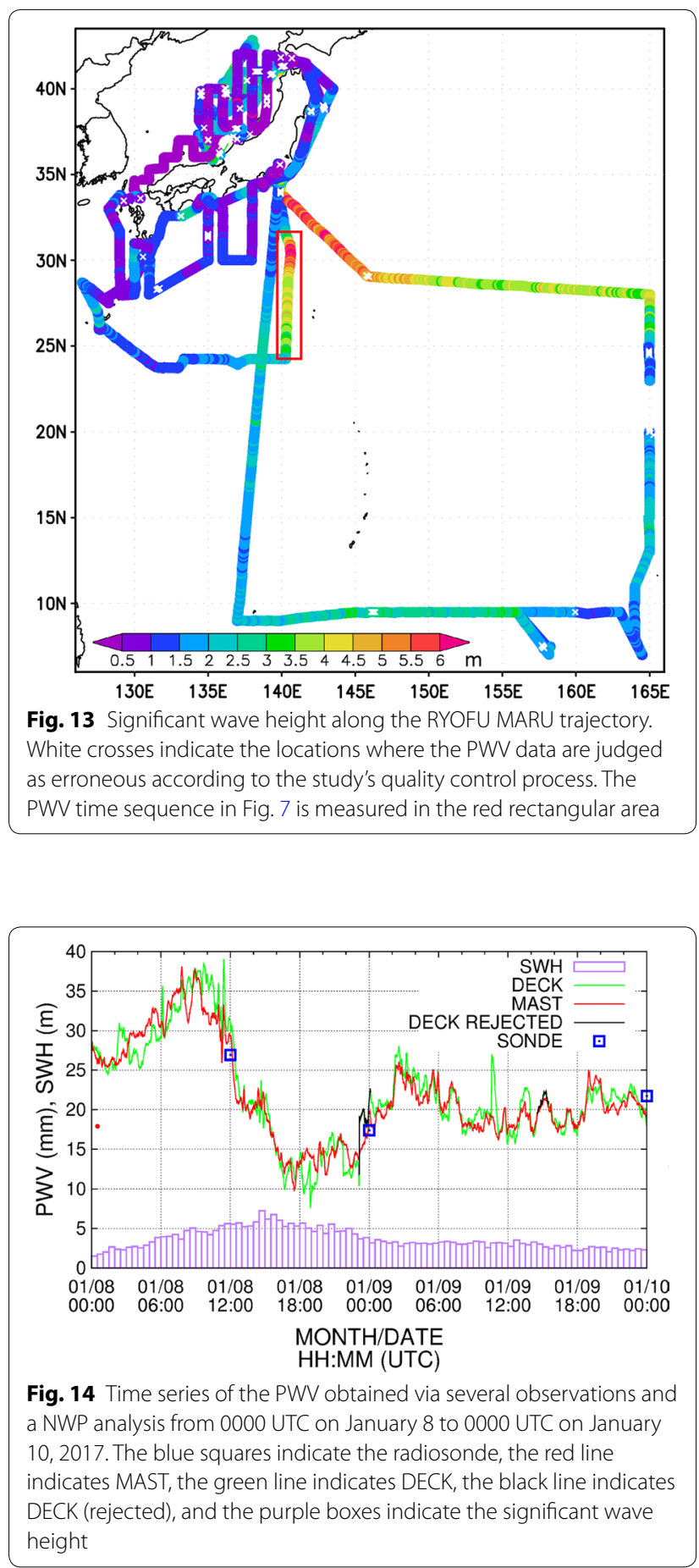

Further investigation is needed about the issues, but, at least, we have not found the evidences of effects of above elements. The above three conditions are related to the degree of three-dimensional antenna movement. Investigation on limitation of ocean platform GNSS measurement for PWV is one of the remaining issues. (c) The relationship between the errors in the GNSS PWV and the estimated coordinates should be investigated in the future.

As shown in Fig. 9, GNSS PWV errors show a certain relation with estimated antenna altitude. Errors in estimated vertical coordinate affect GNSS PWV estimation (e.g., Beutler et al. 1998; Shoji et al. 2000). Figure 9 only shows estimated antenna altitude and does not show vertical coordinate error. In the future, we need to evaluate analyzed vertical coordinates by comparing other observations, such as satellite-borne sea surface altimeter.

(d) Radio wave ducting could cause large error.

Large under estimation of GNSS PWV compared to a radiosonde launched at 2331UTC on June 10, 2017, is discussed with relation to radio wave ducting. To avoid ducting effect, higher elevation cutoff angle might be one answer. We need to carefully investigate the optimum elevation cutoff for ocean platform GNSS observation avoiding multi-path and/or ducting effect while ensuring sufficient number of observation.

\section{Abbreviations}

GEONET: GNSS Earth Observation Network; GNSS: Global Navigation Satellite System; GPS: Global Positioning System; GSI: Geospatial Information Authority of Japan; JAXA: The Japan Aerospace Exploration Agency; JMA: Japan Meteorological Agency; MADOCA: Multi-GNSS Advanced Demonstration tool for Orbit and Clock Analysis; PCV: Phase Center Variation; PPP: Precise Point Positioning; PWV: Precipitable Water Vapor; WVR: Water Vapor Radiometer; ZHD: Zenith Hydrostatic Delay; ZTD: Zenith Tropospheric Delay; ZWD: Zenith Wet Delay.

\section{Authors' contributions}

Shoji Y., K. Sato, M. Yabuki, and T. Tsuda designed the study, developed the methodology, collected the data, performed the analysis, and wrote the manuscript. All authors read and approved the final manuscript.

\section{Author details}

${ }^{1}$ Meteorological Research Institute, Japan Meteorological Agency, Tsukuba, Japan. ${ }^{2}$ Japan Aerospace Exploration Agency, Tsukuba, Japan. ${ }^{3}$ Research Institute for Sustainable Humanosphere, Kyoto University, Kyoto, Japan.

\section{Acknowledgements}

We wish to express our gratitude to two anonymous referees for their important comments that enabled us to correct our misunderstandings and to improve the manuscript significantly. The campaign observation was funded by a research grant for Mission Research for Sustainable Humanosphere from the Research Institute for Sustainable Humanosphere (RISH) at Kyoto University, "Study on accuracy improvement of shipborne GNSS water vapor measurement."A part of the study was also supported by JSPS KAKENHI Grants 16H06310. RTKLIB version 2.4.2 (patch 12) was downloaded from the following link; https://github.com/tomojitakasu/RTKLIB/archive/master.zip. The authors would like to express their sincere appreciation for Mr. Tomoji Takasu for his valuable comments and supports for the GNSS analysis. The GEONET observation data were acquired from the ftp server of the Geospatial Information Authority of Japan (GSI) in RINEX format. MADOCA real-time product was provided by JAXA via the Internet (https://ssl.tksc.jaxa.jp/madoca/ public/public_index_en.html). 


\section{Competing interests}

The authors declare that they have no competing interests.

\section{Availability of data and materials}

The data and materials used in this research are available on request basis to the corresponding author, Dr. Yoshinori Shoji (yshoji@mri-jma.go.jp).

\section{Ethics approval and consent to participate}

Not applicable.

\section{Consent for publication}

Not applicable.

\section{Funding}

The campaign observation was funded by a research grant for Mission Research for Sustainable Humanosphere from the Research Institute for Sustainable Humanosphere (RISH) at Kyoto University, "Study on accuracy improvement of shipborne GNSS water vapor measurement."

\section{Publisher's Note}

Springer Nature remains neutral with regard to jurisdictional claims in published maps and institutional affiliations.

Received: 29 August 2017 Accepted: 25 October 2017

Published online: 03 November 2017

\section{References}

Benevides P, Catalao J, Miranda PMA (2015) On the inclusion of GPS precipitable water vapour in the nowcasting of rainfall. Nat Hazards Earth Syst Sc 15:2605-2616. https://doi.org/10.5194/nhess-15-2605-2015

Beutler G, Bauersima I, Gurtner W, Rothacher M, Schildknecht T, Geiger A (1998) Atmospheric refraction and other important biases in GPS carrier phase observation. In: Atmospheric effects on geodetic measurements, monograph, 12, School of Surveying, University of New South Wales, Kensington, pp 15-43

Bevis M, Businger S, Herring TA, Rocken C, Anthes RA, Ware RH (1992) GPS meteorology: remote sensing of atmospheric water vapor using the global positioning system. J Geophys Res 97:15787-15801

Boehm J, Werl B, Schuh H (2006) Troposphere mapping functions for GPS and very long baseline interferometry from European Centre for MediumRange Weather Forecasts operational analysis data. J Geophys Res 111:B02406. https://doi.org/10.1029/2005JB003629

Boniface K, Champollion C, Chery J, Ducrocq V, Rocken C, Doerfinger E, Collard P (2012) Potential of shipborne GPS atmospheric delay data for prediction of Mediterranean intense weather events. Atmos Sci Lett 13(4):250256. https://doi.org/10.1002/asl.391

Boudouris G (1963) On the index of refraction of air, the absorption and dispersion of centimeter waves by gasses. J Res Natl Bur Stand Sect 67D:631-684

Chadwell CD, Bock Y (2001) Direct estimation of absolute precipitable water in oceanic regions by GPS tracking of a coastal buoy. Geophys Res Lett 28:3701-3704. https://doi.org/10.1029/2001GL013280

Elgered G, Davis JL, Herring TA, Shapiro II (1991) Geodesy by radio interferometry: water vapor radiometry for estimation of the wet delay. J Geophys Res 96:6541-6555

Fujita M, Kimura F, Yoneyama K, Yoshizaki M (2008) Verification of precipitable water vapor estimated from shipborne GPS measurements. Geophys Res Lett 35:L13803. https://doi.org/10.1029/2008GL033764

Fujita M, Wada A, Iwabuchi T, Rocken C (2014) Tropospheric monitoring over the ocean using a shipborne GNSS receiver. In: Proceedings of the 27th international technical meetings of the ION satellite division, pp 1085-1089
Guerova G, Jones J, Douša J, Dick G, de Haan S, Pottiaux E, Bock O, Pacione R, Elgered $G$, Vedel H, Bender M (2016) Review of the state of the art and future prospects of the ground-based GNSS meteorology in Europe. Atmos Meas Tech 9:5385-5406. https://doi.org/10.5194/amt-9-5385-2016 Ishikawa Y (2010) The use of ground based GPS data tin mesoscale analysis. In: Additional volume of the annual report of numerical prediction division vol 56, pp 54-60 (in Japanese)

Kato T, Aranami K (2005) Formation factors of 2004 Niigata-Fukushima and Fukui heavy rainfalls and problems in the predictions using a cloudresolving model. SOLA 1:1-4. https://doi.org/10.2151/sola.2005-001

Li G-C, Guo L-X, Liang Y (2010) Simulation modelling the GPS signal propagation in the tropospheric ducts. In: Proceedings of the 9th international symposium on antennas, propagation and EM theory, 592-595. https:// doi.org/http://doi.org/10.1109/ISAPE.2010.5696535

Mateus P, Giovanni N, João C (2015) Uncertainty assessment of the estimated atmospheric delay obtained by a numerical weather model (NMW). IEEE Trans Geosci Remote Sens 53(12):6710-6717

Petit G, Luzum B (eds.) (2010) IERS Technical Note No. 36, IERS Conventions (2010)

Rocken C, Johnson J, Van Hove T, Iwabuchi T (2005) Atmospheric water vapor and geoid measurements in the open ocean with GPS. Geophys Res Lett 32:L12813. https://doi.org/10.1029/2005GL022573

Shi-Jie F, Jian-Fei Z, Xiu-Ying P, Su-Qin W, Yan-Xiong L, Ke-Fei Z (2016) Validation of atmospheric water vapor derived from ship-borne GPS measurements in the Chinese Bohai Sea. Terr Atmos Ocean Sci 27:213-220. https://doi. org/10.3319/TAO.2015.11.04.01(A)

Shoji Y, Nakamura H, Aonashi K, Ichiki A, Seko H, Members of GPS, MET Japan summer Campaign (2000) Semi-diurnal and diurnal variation of errors in GPS precipitable water vapor at Tsukuba, Japan caused by site displacement due to ocean tidal loading. Earth Planets Space 52:685-690. https:// doi.org/10.1186/BF03352264

Shoji Y, Nakamura H, Iwabuchi T, Aonashi K, Seko H, Mishima K, Itagaki A, Ichikawa R, Ohtani R (2004) Tsukuba GPS dense net campaign observation: improvement in GPS analysis of slant path delay by stacking one-way postfit phase residuals. J Meteor Soc Japan 82(1B):301-314

Shoji Y, Kunii M, Saito K (2009) Assimilation of nationwide and global GPS PWV Data fora heavy rain event on 28 July 2008 in Hokuriku and Kinki, Japan. SOLA 5:045-048

Shoji Y, Sato K, Yabuki M, Tsuda T (2016) PWV Retrieval over the ocean using shipborne GNSS receivers with MADOCA real-time orbits. SOLA 12:265-271. https://doi.org/10.2151/sola.2016-052

Takasu T (2013) RTKLIB 2.4.2 manual. http://www.rtklib.com/prog/ manual_2.4.2.pdf. Accessed 5 October 2017

World Meteorological Organization (2017) Satellite status. http://www.wmo. int/pages/prog/sat/satellitestatus.php. Accessed on 5 October 2017

Zhou F-C, Song X, Leng P, Wu H, Tang B-H (2016) An algorithm for retrieving precipitable water vapor over land based on passive microwave satellite data. Adv Meteorol 2016:1-11. https://doi.org/10.1155/2016/4126393

Zumberge JF, Heflin MB, Jefferson DC, Watkins MM (1997) Precise point positioning for the efficient and robust analysis of GPS data from large networks. J Geophys Res 102(B3):5005-5017

\section{Submit your manuscript to a SpringerOpen ${ }^{\circ}$ journal and benefit from:}

- Convenient online submission

- Rigorous peer review

- Open access: articles freely available online

- High visibility within the field

Retaining the copyright to your article

Submit your next manuscript at springeropen.com 